\title{
Inverse Relationship between Platelet Density and Reactivity Alterations at Coronary Angiography
}

\author{
P. Järemo ${ }^{a}$ T.L. Lindahl ${ }^{b}$ S.G. Fransson ${ }^{c}$ M. Milovanovic ${ }^{a}$ \\ E. Logander ${ }^{a}$ A. Richter ${ }^{a}$ \\ Departments of a Cardiology, ${ }^{b}$ Clinical Chemistry and ${ }^{\mathrm{c}}$ Thoracic Radiology, Linköping \\ University Hospital, Linköping, Sweden
}

\section{Key Words \\ Coronary angiography · Flow cytometer . \\ Platelets · Platelet density}

\begin{abstract}
This work investigates relationships between platelet density and reactivity. 21 individuals subject to coronary angiography were studied. Peak platelet density was analyzed using a newly developed electronic device. The apparatus measures light transmission through test tubes containing density-separated platelets, thus allowing an estimation of the platelet distribution in the gradient. A flow cytometry technique was used for determining platelet reactivity after stimulating with ADP. Platelet counts, mean platelet volumes, peak platelet density and platelet reactivity were determined immediately before (day 1) and $24 \mathrm{~h}$ after cardiac catheterization (day 2). For all parameters changes during the day of angiography were compared with platelet
\end{abstract}

\begin{tabular}{ll}
\hline KARGER & ( ) 2001 S. Karger AG, Basel \\
0301-0147/01/0311-0055\$17.50/0 \\
$\begin{array}{l}\text { E-Mail karger@karger.ch } \\
\text { www.karger.com }\end{array}$ & $\begin{array}{l}\text { Accessible online at: } \\
\text { www.karger.com/journals/hae }\end{array}$
\end{tabular}

density alterations. The subjects were divided into two groups according to density changes at angiography. Group 1 individuals showed density alterations (i.e. day 2 - day 1 value) $\geq-8 \times 10^{-5} \mathrm{~kg} / \mathrm{l}$. In contrast, group 2 subjects either displayed density changes $<-8 \times 10^{-5} \mathrm{~kg} / \mathrm{l}$ or grossly disturbed platelet density patterns on day 2 . Before angiography both groups had similar platelet counts and volumes. Then platelet reactivity when stimulating with ADP did not differ significantly between the two groups. After angiography, the number of fibrinogen-positive cells when stimulating with ADP rose by $6 \pm$ $8 \%$ for group 2 patients. The corresponding figure for group 1 was $-1 \pm 6 \%$. The difference was significant $(p=0.01)$. No such relationships were found when comparing density alterations and changes of platelet counts and volumes. We conclude that in this study platelet density alterations at coronary angiography are inversely related to variations of platelet reactivity.

Copyright $\odot 2001$ S. Karger AG, Basel

\footnotetext{
Petter Järemo, MD

Department of Cardiology

Linköping University Hospital

SE-581 85 Linköping (Sweden)

Fax +4611125662, E-Mail petter.jaremo@beta.telenordia.se
} 


\section{Introduction}

Platelets vary greatly in buoyant density within the density span 1.040-1.080 kg/l [1]. High-density platelets are more reactive, e.g. they adhere more rapidly [2]. In addition, high-density populations contain more granules and mitochondria and elevated levels of glycogen [3]. Eleveted platelet density has been found in patients having acute myocardial infarction [4] and active inflammatory bowel disease [5]. In contrast, individuals with myeloproliferative disorders appear to have low-density platelets [6]. Some workers suggest that platelets decrease in density during their life span [7]. However, evidence exists favoring the contrasting view that there is a significant variability in the density of newly formed platelets [8].

A recent paper [9] describes a computerized apparatus for measuring light transmission through test tubes containing densityseparated platelets. The transmitted light reflects the distribution of platelets in the gradient. Thus, it is possible to determine the platelet density peak in subjects having a normal distribution of platelet density. However, healthy individuals frequently fail to show platelets having a normal density distribution [9] making it difficult to identify a platelet density peak.

This study investigates relationships between platelet density and reactivity. Peak platelet density was determined using the aforementioned apparatus [9]. Platelet reactivity, i.e. the ADP-evoked capability of fibrinogen binding, was measured with a flow cytometry technique [10].
Table 1. Clinical characteristics of the patients with stable angina pectoris

\begin{tabular}{lcc}
\hline & Group 1 & Group 2 \\
\hline Number of patients & 11 & 10 \\
Age (mean value), years & 61 & 63 \\
Sex (m/f) & $10 / 1$ & $6 / 4$ \\
Current smokers, \% & 0 & 20 \\
ACE inhibitors, \% & 9 & 10 \\
Aspirin, \% & 82 & 90 \\
$\beta$-Blockers, \% & 64 & 90 \\
Calcium antagonists, \% & 18 & 30 \\
Diuretics, \% & 18 & 40 \\
Oral nitrates, \% & 73 & 70 \\
\hline
\end{tabular}

Group 1 subjects had density alterations (day 2 value - day 1 value) $\geq-8 \times 10^{-5} \mathrm{~kg} / \mathrm{l}$.

Group 2 individuals either displayed density changes (day 2 value - day 1 value) $<-8 \times 10^{-5} \mathrm{~kg} / \mathrm{l}$ or grossly disturbed platelet density patterns on day 2 .

\section{Material and Methods}

Platelet Density Measurements

Continuous Percoll (Pharmacia, Uppsala, Sweden) gradients were employed for separating platelets according to density [9]. The device used for measuring platelet density peaks has been described extensively [9]. It consists of a stepping motor moving a test tube containing density-separated platelets between a halogen lamp and a potentiometer. The latter is connected to a personal computer. Light transmission variations through the gradient are recorded allowing an estimate of the platelet distribution in the test tube. The position of the platelet peak in the gradient was compared with particles of known density (Pharmacia) permitting the determination of the platelet density peak [9].

\section{Flow Cytometry}

Flow cytometry was performed using a Cytoron Absolute Flow Cytometer (Ortho, Raritan, N.J.). The detailed procedure including sample preparation, chemicals and buffers has been described before [10, 11]. The samples were always run in duplicate. An ADP solution was employed (final concentration 0.6 $\mu \mathrm{mol} / \mathrm{l})$ to activate platelets. Fluorescein isothiocya- 
Table 2. Platelet characteristics (mean $\pm \mathrm{SD}$ ) before coronary angiography (day 1)

\begin{tabular}{|c|c|c|c|}
\hline & $\begin{array}{l}\text { Platelet } \\
\text { counts } \\
\times 10^{12} / 1\end{array}$ & $\begin{array}{l}\text { Mean } \\
\text { platelet } \\
\text { volume, } \mathrm{fl}\end{array}$ & $\begin{array}{l}\text { Fibrinogen-positive cells } \\
\text { when stimulating with } \\
0.6 \mu \mathrm{mol} / 1 \mathrm{ADP}, \%\end{array}$ \\
\hline Group $1(n=11)$ & $227 \pm 32$ & $9.3 \pm 1.2$ & $37 \pm 14$ \\
\hline Group $2(n=10)$ & $238 \pm 63$ & $9.0 \pm 1.1$ & $31 \pm 9$ \\
\hline $\mathrm{p}$ value & NS & NS & NS \\
\hline
\end{tabular}

Group 1 showed density alterations (day 2 value - day 1 value) $\geq-8 \times$ $10^{-5} \mathrm{~kg} / \mathrm{l}$.

Group 2 either displayed density changes (day 2 value - day 1 value) $<-8 \times 10^{-5} \mathrm{~kg} / \mathrm{l}$ or grossly disturbed platelet density patterns on day 2 .

NS $=$ Not significant nate-conjugated chicken anti-human fibrinogen (Biopool, Umeå, Sweden) was used to mark platelet-bound fibrinogen. The latter correlates to the degree of platelet activation. A phycoerythrin-conjugared monoclonal antibody directed towards GPIb (Dako AS, Glostrup, Denmark) was employed as a platelet-identifying agent. A negative control that was run simultaneously included identical preparation steps but EDTA (10 $\mathrm{mmol} / \mathrm{l}$ ) was added to prevent the platelet fibrinogen binding. Platelets with fluorescence intensity higher than the negative control were identified as fibrinogenpositive platelets.

Experimental Protocol and Analytical Procedures We investigated 21 patients with stable angina pectoris (table 1). Individuals with an ongoing myocadial infarction, unstable angina or diabetes mellitus were excluded. Coronary angiography was performed using standard procedures [12]. An ionic contrast medium (ioxoglate) was used. Sampling was done immediately before (day 1) and $24 \mathrm{~h}$ after catheterization (day 2). Peak platelet density and platelet reactivity when stimulating with ADP were determined. In addition, platelet counts and volumes were determined within $0.5 \mathrm{~h}$ after anticoagulation with EDTA. The Ethics Committee of Linköping University Hospital granted ethical permission. Continuous variables are summarized as mean \pm SD. The Student $t$ test for unpaired data was employed for statistical evaluation. A Technicon $\mathrm{H}^{*} 3$ (Bayer-Technicon, Tarrytown, N.Y.) was used for measuring routine platelet parameters. Changes during the day of angiography were determined by subtracting the day 1 value from the corresponding day 2 value.

Platelet Density and Reactivity

\section{Results}

The subjects were divided into two groups consisting of 11 and 10 individuals, respectively (table 1). Group 1 had density alterations (i.e. day 2 value - day 1 value) $\geq-8 \times$ $10^{-5} \mathrm{~kg} / \mathrm{l}$. Group 2 either displayed density changes $<-8 \times 10^{-5} \mathrm{~kg} / \mathrm{l}$ or disturbed platelet density [9] on day 2. Group 1 included 10 males and 1 female. The corresponding figures for group 2 were 6 and 4, respectively. The age of the patients in the two groups proved to be similar but group 2 individuals were on more medications and they were more often smokers. Basic biochemical characteristics are given in table 2. It appears that group 1 individuals had slightly elevated platelet reactivity when stimulating with ADP. Furthermore, their platelet volumes were higher and they had lower platelet counts. These differences, however, failed to reach statistical significance (table 2). Individual results for platelet density are shown in figure 1 . The arrow heads indicate the day 2 values. It was difficult to determine a platelet density peak in two group 2 individuals. The remainder had lower density after angiography (day 2). Group 1 subjects demonstrated a different platelet density behavior as all pa- 
Fig. 1. Individual results for platelet density alterations at angiography. Platelet density was measured immediately before angiography (day 1) and $24 \mathrm{~h}$ after the procedure (day 2). The arrow heads indicate the day 2 values. The subjects were divided into two groups according to density alterations at angiography. Group 1 showed density alterations (day 2 value - day 1 value) $\geq-8 \times 10^{-5} \mathrm{~kg} / \mathrm{l}$. Group 2 either displayed density changes (day 2 value - day 1 value) $<-8 \times$ $10^{-5} \mathrm{~kg} / \mathrm{l}$ or grossly disturbed platelet density patterns (DD) on day 2 .

Table 3. Platelet alterations (mean $\pm \mathrm{SD}$ ) at the day of coronary angiography

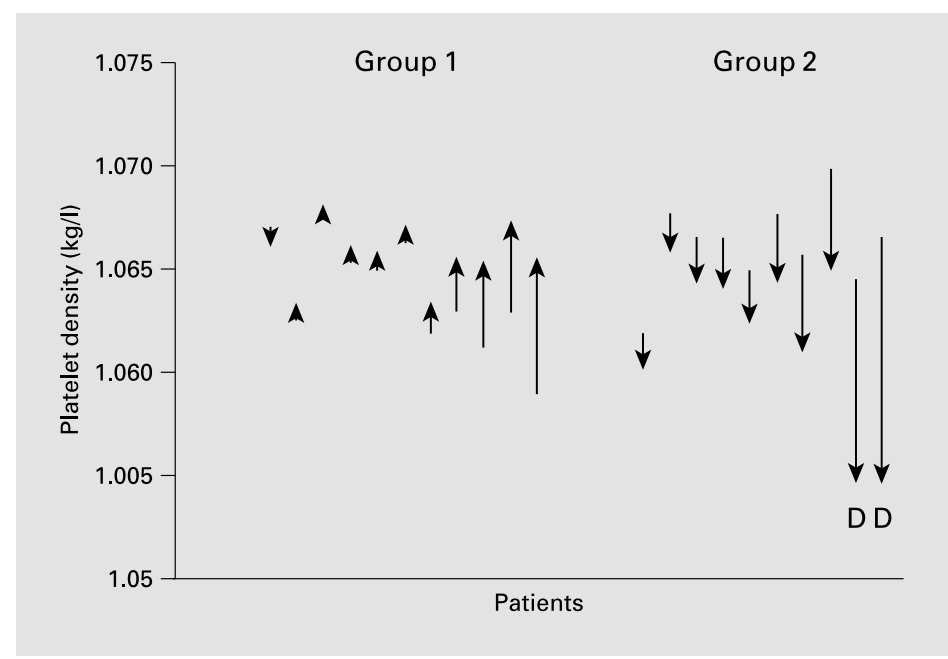

Group 1 showed density alterations (day 2 value - day 1 value) $\geq-8 \times$ $10^{-5} \mathrm{~kg} / \mathrm{l}$.

Group 2 either displayed density changes (day 2 value - day 1 value) $<-8 \times 10^{-5} \mathrm{~kg} / \mathrm{l}$ or grossly disturbed platelet density patterns on day 2 .

$\mathrm{NS}=$ Not significant.

1 Day 2 value - day 1 value, i.e. the calculation represents changes on the day of angiography.

tients with one exception had a higher platelet density on day 2 (fig. 1). Table 3 summarizes the results of the present study. On day 2 , group 2 patients demonstrated a highly significant $(\mathrm{p}=0.01)$ elevation of platelet reactivity after ADP stimulation. Platelets from group 1 subjects displayed increased volumes on day 2 , but these alterations did not differ significantly from group 2 values. The platelet counts did not change at angiography.

\section{Discussion}

The present laboratory work investigates possible relationships between platelet density and reactivity. An elevated reactivity after angiography as estimated from flow cytometry measurements proved to be related to a higher platelet density loss (group 2). In contrast, group 1 subjects not having increased reactivity on day 2 displayed less density 
alterations. Consequently, in this study platelet density alterations are inversely related to platelet reactivity.

A liberation or an ongoing consumption of platelet subpopulations may change the density of the whole population. Possible mechanisms include a consumption of activated low-density platelets or the release of highdensity platelets from the bone marrow. We failed to demonstrate significant relationships when comparing density alterations and changes of platelet counts and volumes. Consequently, our study may suggest that when platelet reactivity increases, platelet activation with the subsequent granule release causes density to decrease.

The clinical implications of these findings could be of great interest. Contrast media appear to cause platelet activation measured by P-selectin expression with ionic media causing less activation [13]. The present study shows elevated platelet reactivity after contrast media exposure in group 2 patients. Thus, we demonstrate that some individuals are more susceptible to the platelet-activating effects of contrast media.

This study concerns a homogeneous group of patients with stable angina pectoris. Normally, statistical analysis is performed using collected data from all individuals taking into account possible confounding factors such as sex, smoking and platelet-directed medication. However, 2 individuals (fig. 1) failed to show a normal density distribution [9] making it difficult to determine a platelet density peak. Consequently, we cannot allocate a numerical value for density to them and it is impossible to use the statistics indicated above. Thus, subjects with less density alterations at angiography were compared with individuals having a higher platelet density loss. The latter patients were more often females and were to a greater extent smokers (table 1). It is possible that sex and smoking habits influence platelet behavior at coronary angiography. However, larger clinical trials are necessary to establish such relationships.

We used particles with known density, density marker beads, to calibrate the measurement of platelet density. Consequently, the denotation 'disturbed platelet density' is used when the beads are in their expected positions and it is difficult to identify a platelet density peak. It is feasible that a disorganized Percoll gradient also makes it impossible to recognize a density peak. However, in the latter case the beads used for calibration would be dislocated.

The denotation of platelet density heterogeneity is still debatable. Some investigators believe that it originates during platelet production [8]. Others contend that it is a consequence of events modifying platelets as they age in the circulation [7]. It is evident that the present work supports the latter notion.

\section{Acknowledgments}

The study was supported by grants from the County Council of Östergötland, Sweden. 


\section{References}

1 Chamberlain KG, Froebel M, Macpherson J, Penington DG: Morphometric analysis of density subpopulations of normal human platelets. Thromb Haemost 1988;40:44-49.

2 Polanowska-Grabowska R, Sanghamitra R, Gear ARL: Adhesion efficiency, platelet density and size. Br J Haematol 1992;82:715-720.

3 Chamberlain KG, Seth P, Jones MK, Penington DG: Subcellular composition of platelet density subpopulations prepared using continuous Percoll gradients. Br J Haematol 1989;72:199-207.

4 Martin JF, Plumb J, Kilbey RS, Kishk YT: Changes in volume and density of platelets in myocardial infarction. BMJ 1983;287:456-459.

5 Järemo P, Sandberg-Gertzen H: Platelet density and size in patients with inflammatory bowel disease. Thromb Haemost 1996;75:560561 .
6 Järemo P: Platelet density in essential thrombocythemia and polycythemia vera. Platelets 1999;10:6163.

7 Karpatkin S: Heterogeneity of human platelets. II. Functional evidence suggestive of young and old platelets. J Clin Invest 1969;48: 1083-1087.

8 Penington DG, Straetfield K, Roxburgh AE: Megakaryocytes and the heterogeneity of circulating platelets. Br J Haematol 1976;34:639_ 653.

9 Järemo P: Computerised method for monitoring platelet density distribution. Eur J Haematol 1995;54: 304-309.
10 Lindahl TL, Festin R, Larsson A Studies of fibrinogen binding to platelets by flow cytometry: An improved method for studies of platelet activation. Thromb Haemost 1992;68:221-225.

11 Lundahl TH, Pettersson J, Fagerberg IH, Berg S, Lindahl TL: Impaired platelet function correlates with multiorgan dysfunction. A study of patients with sepsis. Platelets 1998;9:223-225.

12 Reagan K, Boxt LM, Katz J: Introduction to coronary arteriography. Radiol Clin North Am 1994;32: 419-433.

13 Chronos NA, Goodall AH, Wilson DJ, Sigwart U, Buller NP: Profound platelet degranulation is an important side effect of some types of contrast media used in interventional cardiology. Circulation 1993;88: 2035-2044. 